\title{
Ciencia y patronazgo real en el imperio español del siglo XVII: Fray Ignacio Muñoz y su Propuesta de trabajo en Artes Náuticas*
}

\author{
Science and Royal Patronage in the 17th-century \\ Spanish Empire: Friar Ignacio Muñoz and his \\ Work Proposal in Nautical Arts
}

\author{
José María Moreno Madrid \\ ORCID iD: https://orcid.org/0000-0002-9499-3474 \\ Universidade de Lisboa / Centro Interuniversitário de História \\ da Ciência e da Tecnologia, Lisboa, Portugal
}

El objetivo de este artículo es analizar minuciosamente la trayectoria vital de fray Ignacio Muñoz, fraile dominico del siglo XVII enviado a servir a Filipinas. Especial interés reviste la utilización que el dominico hace de sus conocimientos científicos, adaptándolos a las necesidades del imperio español para conseguir el mecenazgo de Felipe IV. La documentación manuscrita del propio Muñoz y la emitida en respuesta por las instituciones españolas son las principales fuentes para el estudio.

Palabras Clave: Ciencia náutica; Mecenazgo Real; Ignacio Muñoz; Filipinas; Nueva España.

The aim of this article is to analyze in depth the life course of Fray Ignacio Muñoz, a seventeenth-century Dominican friar assigned to the Philippines. Particularly relevant is Muñoz's use of his scientific knowledge, as he tailored it to the needs of the Spanish empire in order to obtain the patronage of Philip IV. Muñoz's own handwritten documentation and that produced in response by Spanish institutions are the main sources for the study.

KeYwords: Nautical Science; Royal Patronage; Ignacio Muñoz; Philippines; New Spain.

Copyright: (C) 2021 CSIC. Este es un artículo de acceso abierto distribuido bajo los términos de la licencia de uso y distribución Creative Commons Reconocimiento 4.0 Internacional (CC BY 4.0).

* La investigación que produjo estos resultados ha recibido financiación del European Research Council (ERC), en el marco del programa de investigación e innovación European Union's Horizon 2020 (grant agreement No. 833438). Proyecto "RUTTER: Making the Earth Global: Early Modern Nautical Rutters and the Construction of a Global Concept of the Earth". El autor agradece a Henrique Leitão, Francisco Malta Romeiras, Nuno Vila-Santa, Silvana Munzi y Juan Acevedo sus minuciosas revisiones del texto original, así como sus comentarios y sugerencias para mejorarlo. También agradece a Emiliano Pérez, O.P., la ayuda prestada en el Archivo de la Provincia del Rosario, en el convento de Santo Tomás de Ávila. 


\section{Obertura}

Ignacio Muñoz fue, según José María Cervera Jiménez, «uno de los misioneros científicos españoles más importantes del siglo XVII». ${ }^{1}$ Considerando la inexistencia de estudios dedicados a sus obras científicas, es de suponer que la afirmación hace referencia a la sorprendente trayectoria vital del dominico, que ha llamado la atención de diversos autores desde finales del siglo XIX. Fue el padre Hilario Ocio quien abrió la veda del interés por Ignacio Muñoz en el Compendio de la Reseña Biográfica de los Religiosos de la Provincia de Nuestra Señora del Rosario de la Orden de Predicadores (1895). ${ }^{2}$ Poco después recogieron el guante los jesuitas Pablo Pastells ${ }^{3}$ y Miguel Selga, ${ }^{4}$ cuyas aportaciones fueron utilizadas por el religioso Eladio Neira en la obra Misioneros Dominicos en el Extremo Oriente, 1587-1835, para actualizar la escasa información reunida por Ocio. ${ }^{5}$

A las contribuciones de Pastells y Selga siguió el trabajo del padre Mariano Velasco, ${ }^{6}$ pero hasta la década de 1960 no se realizó el primer estudio sistemático de la vida de Ignacio Muñoz, a cargo del dominico José María González. Los resultados de varios años de investigación y trabajo aparecieron en forma de entrada biográfica en su magnus opus, Historia de las Misiones Dominicanas de China. ${ }^{7}$ Siguiendo las pistas dejadas por Pastells y González, Juan Gil — a partir de la documentación conservada en el Archivo General de Indias - escribió la mejor biografía del dominico hasta la fecha y, paradójicamente, la que ha pasado más desapercibida, incluso para aquellos que han producido nuevas investigaciones sobre Muñoz. ${ }^{8}$ Tal es el caso de Cervera Jiménez que, en su apunte biográfico, exclusivamente refirió a los citados Ocio, González y Selga como fuentes para el estudio del dominico. ${ }^{9}$ Con todo, Ignacio Muñoz no ha gozado de especial interés

1 Cervera Jiménez, 1999, 162.

2 Ocio y Neira, 2000, 64.

3 Colin y Pastells, 1904, I: 210-211; III: 815-816, 824-825.

4 Véase Cervera Jiménez, 1999, 162-164.

5 Ocio y Neira, 2000, 64-65.

6 «Ensayo de Bibliografía de la Prov. Del Smo. Rosario en Filipinas, China, Japón, Formosa y Tungkin. P. M. Velasco, O. P. Tomo II», Archivo Histórico de la Provincia Dominicana de Nuestra Señora del Rosario, convento de Santo Tomás, Ávila (APDA), 5B-Izquierda, Documentación Diversa, tomo $140,192-194$.

7 González, 1967, V: 406-411. Las notas, borradores y referencias documentales compiladas por González sobre Ignacio Muñoz revisten gran interés y pueden ser consultadas en APDA, 3-Izquierda, Biografías, tomos 22, 23 y 24.

8 Gil, 1989, 247-254.

9 Cervera Jiménez, 1999, 162-164. 
en tiempos recientes, aun cuando prestigiosos investigadores han llamado la atención sobre la necesidad de profundizar en su producción científica. ${ }^{10}$ Más allá de la reciente edición de su proyecto para llevar la fe católica a las islas Marianas, ${ }^{11}$ solo encontraremos el nombre de Ignacio Muñoz citado de forma anecdótica en estudios sobre la presencia de la orden de Santo Domingo en Filipinas y su actividad científica. Por ello, este artículo tiene dos objetivos principales. El primero es proporcionar una biografía completa y tan exhaustiva como sea posible del citado fraile, arrojando luz sobre los aspectos más desconocidos de su trayectoria vital y clarificando las informaciones cruzadas e inexactitudes que puedan encontrarse en los diversos apuntes biográficos que ha protagonizado. El segundo busca, a través de una relectura de los documentos bajo el prisma de tendencias más actuales en Historia de la Ciencia, integrar este relato en la literatura sobre ciencia y patronazgo. A lo largo del texto se analizarán las estrategias empleadas por Muñoz para sacar el mayor rédito posible a sus trabajos, constituyendo un ejemplo sumamente detallado de cómo podía explotarse el conocimiento científico en la España del siglo XVII para obtener beneficios sociales y personales.

No son muchos los textos de carácter científico con la firma de Muñoz que han sobrevivido hasta nuestros días. En la Biblioteca Nacional de España se conservan tres: «Observationes diversarum artium», ${ }^{12}$ «Derroteros de los mares de Marruecos, Canarias, América y Filipinas, y otros documentos» ${ }^{13}$ y Manifiesto geométrico, plus ultra de la geometria practica. ${ }^{14}$ Víctor Navarro Brotons identificó uno más en la Real Academia de la Historia, titulado «Operación geométrica synóptica y universal para dividir qualquier angulo rectilíneo en las partes iguales, o proporcionales, que se pidieren», ${ }^{15}$ y Rafal Reichert hizo lo propio con el citado manuscrito «sobre la manutención, y extensión de la Fe en la cordillera de las Islas Marianas, y sus confinantes, y sobre el descubrimiento y conquista de las Islas Australes de

\footnotetext{
10 Tal es el caso de Navarro Brotons, 1999, 107-108.

11 Reichert, 2014.

12 Ignacio Muñoz, «Observationes diversarum artium», c. 1669, Biblioteca Nacional de España, Madrid (BNE), ms. 7111.

13 Ignacio Muñoz, «Derroteros de los mares de Marruecos, Canarias, América y Filipinas, y otros documentos», s. XVII, BNE, ms. 7119. Carmen Martín Rubio (1998, 50-53) publicó un derrotero de las Canarias copiado por Muñoz en esta obra, sin conceder mayor atención al autor.

14 Muñoz, 1684. BNE, 3/48498. BNE, VE/18/11.

15 Ignacio Muñoz, «Operación geométrica synóptica y universal para dividir qualquier angulo rectilíneo en las partes iguales, o proporcionales, que se pidieren», Madrid, 28 de julio de 1670, Real Academia de la Historia, Madrid, Col. Cortés, 9/2782. Navarro Brotons, 1999, 107.
} 
Salomón». ${ }^{16}$ José María González, por su parte, registró hasta cinco obras de su autoría que se han perdido: «Demostratio Geometrica trianguli Ysosceles, in Heptagono regulari»; "Geometría práctica; Novus Geometricae thesaurus»; «Hydrographia Universalis et particularis practica et speculativa»; «Descriptio currum siam; Architectura communis», y «Tabula declinationis solis et stellarum». ${ }^{17}$

Ignacio Muñoz era natural de Valladolid, concretamente, según su propia mano, de Espinosa de los Monteros, en el actual término provincial de Burgos. ${ }^{18}$ Más complicado resulta establecer su fecha de nacimiento, pues las fuentes se contradicen en varias ocasiones; por ello, sugerimos un arco temporal de 1608 a $1612 .{ }^{19}$ De lo que no cabe duda alguna es que, el 6 de mayo de 1634, Ignacio Muñoz fue listado por fray Mateo de la Villa, procurador de la provincia de Filipinas de la orden de Santo Domingo, como uno «de los religiosos que se han de embarcar este año en la flota de la nueba españa para la dicha provincia». ${ }^{20} \mathrm{Sin}$ inconvenientes aparentes, el contingente de dieciséis dominicos acabó tomando tierra en el problemático archipiélago asiático en junio de 1635. Pero apenas dos años después del arribo, contra todo pronóstico, Muñoz buscaba, urgentemente, la manera de escapar de las Filipinas. Claro que, si quería evitar problemas con las autoridades civiles y eclesiásticas, su fuga necesitaba una justificación plausible y un valedor poderoso que le cubriera las espaldas. Muñoz, demostrando ambición y confianza en sus planes, escogió como patrón a Felipe IV, gran soberano de la Monarquía hispánica.

No obstante, ¿qué podía ofrecer un humilde fraile dominico que ni siquiera alcanzaba la treintena de edad para llamar la atención del monarca? En el caso de fray Ignacio Muñoz solo había una respuesta posible: su conocimiento científico. Ese era su salvoconducto, su llave maestra para abrir la puerta de salida de las Filipinas. Claro que un aporte científico estándar

16 Archivo General de la Nación, México (AGN), Reales Cédulas Originales, 14, ff. 263-272. Reichert, 2014, 133-163.

17 González, 1967, V: 407.

18 «Carta de fray Ignacio Muñoz, sobre que se ha detenido en Nueva España para preparar todo lo que quiere presentar acerca del trabajo que propone sobre Hidrografía Universal. Se queja de la violencia con que le ha tratado el virrey para obligarle a pasar a España, y expone los motivos que cree tuvo para ello. Adjunta un memorial que hizo al virrey, y suplica que se le ampare y se le trate con la decencia correspondiente, y que cuando pueda viajar a España se le dé el aviamiento necesario», México, 12 de abril de 1667, Archivo General de Indias, Sevilla (AGI), Filipinas, 86, n. 29.

19 En 1634 se le otorgan 25 años de edad, pero en 1660 Muñoz dice que tiene 50 años; en 1666 , afirma que son 55, y en 1669, 57 años.

20 «Petición del dominico Mateo de la Villa de aprobación de lista», 6 de mayo de 1634, AGI, Filipinas, 80, n. 182. 
nunca despertaría el interés del soberano español, por lo que Muñoz necesitaba hacerle una oferta que no pudiera rechazar. Tan atrevido como brillante, el joven predicador le ofreció ni más ni menos que una serie de herramientas técnico-científicas -instrumentos, cartas náuticas, derroteros- para mejorar el rendimiento de sus flotas en aquellas aguas que tan bien conocía. En otras palabras, le estaba brindando a Felipe IV la posibilidad de darle un nada desdeñable impulso a su imperio a un precio irrisorio. No obstante, las cosas de palacio van despacio; Ignacio Muñoz puso en marcha su plan en 1637, pero, como veremos, solo alcanzó su meta algunas décadas después.

\section{El eregio ilícito de la Congregación de San Pablo}

Fray Diego Collado, religioso dominico que ya había estado en Filipinas y Japón entre 1611 y 1622, consiguió en Roma - a principios de la década de 1630 - el permiso de Propaganda Fide y una letra patente firmada por Nicolás Rodulfo, maestro general de la orden de Santo Domingo, para fundar una misión japonesa independiente de la de Filipinas; no obstante, no contaba con el beneplácito del monarca español. La nueva fundación recibiría el nombre de Congregación de San Pablo y su centro neurálgico sería un colegio en Filipinas que formaría misioneros para enviarlos a China y Japón. ${ }^{21}$ Fray Ignacio Muñoz se había adscrito a esta iniciativa de Collado, al igual que los quince frailes que viajaron con él en $1634 .{ }^{22}$ Bajo el liderazgo de Collado, estos serían los responsables de establecer la nueva congregación en el archipiélago filipino.

Los tres primeros años de Ignacio Muñoz en las Filipinas son probablemente el capítulo más oscuro y desconocido de su biografía. Sin embargo, lejos de jugar un papel marginal en el conflicto desatado por las pretensiones de Collado — que se extendió hasta 1637—, Muñoz se implicó activamente en el proceso, tal y como lo prueba la documentación levantada con motivo del intento de eregio ilícito de la Congregación de San Pablo. ${ }^{23}$

21 Tronu Montané, 2012, 757.

22 González, 1967, V: 408.

23 «La Famosa cuestión del P. Fr. Diego Collado, quien intentó fundar la Congregación de S. Pablo...», APDA, 1-Derecha, Provincia, tomo 12. Cuestiones del Padre Collado, tomo 152, doc. 1. No se pretende en este apartado relatar minuciosamente los sucesos derivados de la llegada de la congregación de San Pablo a las Filipinas, sino localizar y destacar las intervenciones de Ignacio Muñoz en pos de esclarecer su rol en el episodio. Sobre estos sucesos, véase el testimonio del obispo de Nueva Segovia, Diego Aduarte, 1693, I: 719-723. 
Al llegar a Filipinas, fue precisamente Ignacio Muñoz quien inició la tentativa de eregio, siendo el responsable de notificar las patentes de Roma a Domingo González, padre provincial del Rosario, el 24 de junio de 1635. Por respuesta recibió que aquellos papeles no eran suficientes al no haber sido ratificados por el Consejo de Indias, lo cual corroboró Felipe IV más adelante, ${ }^{24}$ aunque Collado mintiese diciendo que «ya estaba hecha esa diligencia». Advertía el provincial que, si Collado procediese con la fundación de la congregación, sería «forçoso proceder contra él con rigor como contra desobediente a su prelado». ${ }^{25}$

El rechazo del padre provincial a las pretensiones de Collado se tradujo en diversas restricciones y «agravios» para él y sus adeptos. Con especial hincapié, incidió en que se recortasen las largas barbas y la cabellera que traían, lo que molestó especialmente al líder por ser este el «disfraz» que había ideado para aventurarse en tierras niponas, con la venia del propio maestro general. Sobre este atropello refiere Muñoz que, la noche del 24 de junio, un emisario de Domingo González les advirtió que si no aligeraban sus cabellos no podrían decir misa; y, efectivamente, cuando al siguiente intentaron oficiar sin acatar la orden, el sacristán les negó el derecho en nombre del padre provincial. Finalmente tuvieron que obedecer, «compelidos de la violencia física» que suponía prohibirles la celebración de la misa. ${ }^{26}$

Empeñado Collado en que el padre provincial aceptase la autoridad de sus licencias, envió nuevamente a Muñoz a notificarlas el 27 de junio de 1635. Idéntica fue la réplica de González, si bien esta vez Muñoz contestó insistiendo en que «se habían visto en consejo las dichas letras patentes como consta del común estilo que para traer religiosos a las partes de las Indias siempre se ha tenido y tiene». ${ }^{27}$ Pero el provincial no dio su brazo a torcer y Collado, impotente, tuvo que reconsiderar su estrategia. La opción violenta se impuso y, en mayo de 1636, con apoyo militar de Sebastián Hurtado de Corcuera, gobernador y capitán general de Filipinas, se inició la toma de los conventos del Parián de los Sangleyes y de Los Reyes, del hospital de San Gabriel, así como del pueblo de Binondo. ${ }^{28}$

24 «Carta que escribió su Majestad al Venerable y Devoto padre Provincial de la Orden de Santo Domingo de las Islas Filipinas», 21 de febrero de 1637, documento mecanografiado en APDA, 1-Derecha, Cédulas Reales, tomo 18.

25 «La Famosa cuestión del P. Fr. Diego Collado...», APDA, 1-Derecha, Provincia, tomo 12 Cuestiones del Padre Collado, tomo 152, doc. 1, f. 257v.

26 Ibidem, ff. $257 \mathrm{v}-259 \mathrm{v}$.

27 Ibidem, f. 259r.

28 Ibidem, f. 355r. 
Alarmadas, las instituciones civiles y eclesiásticas pusieron en marcha la «Causa conservatoria a favor de la provincia del Santo Rosario de la Orden de Predicadores de las Islas Filipinas», para resolver la situación originada por Collado.$^{29}$ Entre las diversas decisiones tomadas por esta suerte de «comisión» destacó la amenaza de pública excomunión a dicho cabecilla, si no renunciaba a las casas tomadas y se entregaba. ${ }^{30}$ Esta le fue notificada por el notario apostólico, Juan Bautista de Aragón, el 18 de noviembre de 1636, en la llamada Casa del Ministerio del Parián de los Sangleyes. Tras escucharlo, Collado le pidió que se lo diera por escrito, entregándole este un traslado simple del auto. No obstante, la situación acabó por complicarse. Según relata el propio Aragón en un segundo testimonio, los frailes Ignacio Muñoz y Francisco de Armella, testigos de los hechos, ${ }^{31}$ le espetaron que «a nosotros no nos lo notifiquen, que con nosotros no tiene que ver», y Collado los secundó exclamando «en mi casa no quiero que notifique nada a nadie»; y no contentos con la vehemencia verbal, lo agarraron entre los tres y amenazaron con encerrarlo en una celda, de lo cual se libró el notario zafándose de sus agresores y huyendo escalera abajo. ${ }^{32}$

Muñoz - leal a su causa - reaparecerá en las fuentes en la última fase del proceso, cuando las autoridades filipinas aprobaron el desalojo de los espacios ocupados por la facciosa congregación. El 6 de septiembre de 1637, Alonso de San Bernardo, prior del convento de San Sebastián, irrumpió en el de Los Reyes para expulsar de allí a los frailes Juan Cazón, Diego Rodríguez y el susodicho Muñoz. Paralelamente, en el hospital de San Gabriel, extramuros de Manila, Diego Collado aceptaba su derrota y se encaminaba al convento de Santo Domingo. ${ }^{33}$ Tras la restitución de las casas a la provincia del Santo Rosario, la Congregación de San Pablo fue disuelta y Collado desterrado a Cagayán, donde según el padre Mariano Velasco «se portó como un religioso digno, de mucha virtud de noble y elevado carácter». ${ }^{34}$

Cabe preguntarse cuál fue el destino de Ignacio Muñoz, poco menos que la mano derecha del líder sedicioso. Previsor y celoso de la suerte que podía correr su rebelión, Collado había hecho valer sus privilegios ante

29 Ibidem, f. $277 \mathrm{r}$.

30 Ibidem, ff. 288v, 301v, 303v.

31 Ibidem, f. 301r.

32 Ibidem, f. 302r-302v.

33 Ibidem, f. 337v.

34 «Ensayo de Bibliografía de la Prov. Del Smo. Rosario en Filipinas, China, Japón, Formosa y Tungkin. P. M. Velasco, O.P. Tomo II», APDA, 5B-Izquierda, Documentación Diversa, tomo 140, 34. 
fray Hernando Guerrero, arzobispo metropolitano de las Filipinas, ${ }^{35}$ con el fin de salvaguardar el futuro de sus cuatro acólitos más fieles, entre los que se encontraba Muñoz. El 18 de julio de 1637, Guerrero declaraba que estaba «contento de resarcir el agravio que de lo hecho pueda haber resultado contra los dichos religiosos, y su buen nombre, honor y reputación y exempción de sus privilegios», para lo cual ordenó que se quemasen en presencia suya y del padre Collado todos «los escritos que en razón de esto se han hecho, original, copia o copias, sin que quede de ellos reliquia: ningún papel, traslado, sumario ni rastro de todos ellos en mi poder ni de otro alguno». ${ }^{36}$ En definitiva, la intermediación del arzobispo Guerrero habría encubierto parcialmente la participación de Muñoz en las operaciones de la Congregación de San Pablo para erigir una provincia dominica independiente de Filipinas; no obstante, su situación no dejaría de ser controvertida pues, a diferencia de la mayoría de seguidores de Collado, Muñoz nunca accedió a incorporarse a la provincia del Santo Rosario. ${ }^{37}$

\section{La ruta de la India}

Tras estas disputas, no sorprende, que en algún momento de 1637 Ignacio Muñoz comunicase a Sebastián Hurtado de Corcuera su deseo de volver «a las partes de Europa a hacer presentación de un instrumento hallado con mi industria con que se puede saber la altura [latitud] a todas las horas de el día». ${ }^{38}$ El gobernador, afín al dominico, atendió a su petición al año siguiente, determinando que el viaje se realizaría por la menos frecuente «vía de la India», ya que Muñoz no había llegado a tiempo a Cavite, de donde había partido el Galeón de Manila. Así pues, con su licencia en orden, el fraile se reunió con Alejo de Mezquita (o Amezqueta), capitán mayor de los viajes de Macán, para embarcarse de nuevo y poner fin a

$35 \ll[$ Fr. Diego Collado] había ganado a su partido [...] al arzobispo de Manila, Excmo. Sr. Guerrero, que había depositado en el toda su confianza», APDA, 5B-Izquierda, Documentación Diversa, tomo 140.

36 «La Famosa cuestión ...», APDA, 1-Derecha, Provincia, tomo 12. Cuestiones del Padre Collado, tomo 152, doc. 1, f. 275r-275v.

37 Se buscó también una coartada para esos dos años en Filipinas, proclamando que había ejercido como «Cathedrático y Magisterio de Philosophia de la Real Universidad de Sto. Tomás de Manila». González, 1967, V: 408.

38 «Licencia a Fray Ignacio Muñoz para pasar a España por la vía de la India, embarcando con Alejo de Mezquita Pereira o cualquier otro dueño de navío», Manila, 27 de septiembre de 1638, AGI, Filipinas, 86, n. 29. 
su estancia en Filipinas. Para sorpresa del predicador, Mezquita le negó el acceso a su navío, arguyendo que el virrey de la India, Pero da Silva, le había ordenado no llevar a ningún religioso castellano de aquellas islas si no fuera por una cuestión de «negocios importantes», lo cual debía constar por papeles. Nuevamente, Muñoz pidió la intercesión de Hurtado de Corcuera, quien expidió una segunda licencia el 27 de septiembre de 1638, en la que ordenaba a Mezquita, o a «qualquiera otro dueño de navío», que lo dejara embarcar en su camino a la India. ${ }^{39}$

A su llegada a la India, Muñoz advirtió que se respiraba un ambiente enrarecido. Los albores del proceso de restauración de la independencia portuguesa, cada vez más nítido en la Península Ibérica, ${ }^{40}$ comenzaban a permear también en aquellas tierras orientales. Ante él se abría un horizonte complejo, pues carecía de recursos para regresar a España por tierra, y un eventual encarcelamiento en el Portugal continental descartaba también la opción marítima. Muñoz presentó esta eventualidad con cierto dramatismo, pero lo cierto es que su objetivo principal estaba cumplido: poner tierra de por medio con las Filipinas.

En 1658 se encontraba en la ciudad portuguesa de Negapatão (Nagapattinam), donde asistió a la toma de la misma por los holandeses en colaboración con los naturales. Esa era la oportunidad que Muñoz había estado esperando. Valiéndose de la situación pacífica que imperaba por aquel entonces entre España y las Provincias Unidas, Muñoz solicitó a los holandeses pasaje para continuar su camino a Europa, pero le fue denegado por su condición de religioso. Frustrado, surcó el golfo Gangético, haciendo escala en el reino de Siam, para desembarcar nuevamente en Manila a finales de $1659 .{ }^{41}$ Tras dos décadas, llegó a su fin la primera tentativa de Muñoz para abandonar las Filipinas y regresar a España. Distaba mucho de poder considerarse un éxito, pero tampoco puede entenderse como un absoluto fracaso en el marco de sus planes, pues habría logrado ampliar sus conocimientos científicos y reunir materiales y recursos que le permitiesen elaborar una propuesta sin fisuras a la que su monarca no pudiera resistirse. Además de impartir Filosofía y Teología en el colegio de Santo Tomás de Goa, donde

39 Idem.

40 Véase Bouza, 1991, 218-220.

41 «Carta de fray Ignacio Muñoz sobre que hace algunos años fue a la India Oriental con licencia del gobernador de Filipinas para pasar a España y ofrecer al rey un servicio importante tocante al arte de la navegación. Pide que se ordene al gobernador de Filipinas y virrey de Nueva España que le faciliten el pasaje y aviamiento para estos reinos», Cavite, 9 de julio de 1660, AGI, Filipinas, 86, n. 29. 
le fue concedido el grado de maestro en dicha área ${ }^{42}$ él mismo afirmó que, durante esos años, no dejó «de proseguir siempre incansable, con desvelos continuos, en la especulación de todo lo tocante a la Hydrografia, no solo particular de estos mares, mas también de todo lo descubierto». ${ }^{43}$

\section{De Manila a Acapulco}

A pesar del tiempo transcurrido, el deseo de Muñoz de abandonar las Filipinas seguía ardiendo con la misma intensidad; poco más de medio año en las islas fue suficiente para perfeccionar su oferta al monarca. El 9 de julio de 1660 escribía directamente a Felipe IV, maravillándose de la precisión con la que sus enemigos conocían los secretos hidrográficos de las aguas españolas, lo que contrastaba con la poca destreza que ostentaban los pilotos al servicio de la Monarquía hispánica ${ }^{44}$ Muñoz redactaba estas líneas con intencionada osadía, persiguiendo el evidente objetivo de llamar la atención del rey. Ya en su primer intento de regresar a España, la oferta de su novedoso astrolabio había sido suficiente para convencer al gobernador de Filipinas. Ahora, el dominico contaba con otras armas. Sobre la mesa estaba poniendo los principales problemas que aquejaban a la marinería española en aguas orientales y se proponía entregarle las soluciones al rey.

Así pues, Ignacio Muñoz prometía a Felipe IV reducir los accidentes navales en la entrada a Cavite, componiendo para ello una carta de navegar competente; cartas hidrográficas y derrotas de «todo el mar de Oriente hasta el Cabo de Buena Esperanza, [...] y la mayor parte del océano de Europa, África y Nuevo Mundo»; un astrolabio de fabricación propia, que permitía conocer la latitud en cualquier momento del día, cuyos grados eran «casi treinta veces mayores» que los de los astrolabios ordinarios - probablemente el que ya había ofrecido para su viaje a través de la India-, y otro instrumento, también de su invención, que facilitaría los cálculos de longitudes. A cambio, solicitaba que se le concediese licencia para regresar a España; eso sí, a gastos pagados por la hacienda real. La astucia y

42 González, 1967, V: 409.

43 «Carta de fray Ignacio Muñoz sobre que hace algunos años fue a la India Oriental...», AGI, Filipinas, 86, n. 29.

44 Gil, 1989, 248. Véase «Carta de fray Ignacio Muñoz sobre que hace algunos años fue a la India Oriental...», AGI, Filipinas, 86, n. 29. 
el cuidado con los que el religioso había concebido su plan salen a la luz más adelante en la carta, impregnando las líneas que siguen a sus atractivas propuestas científicas:

No ay duda, que remitiera las figuras y demonstraciones Mathemáticas de estos dos instrumentos al Real Consejo de Indias de V. Majestad, a quien pertenecen estas materias. Empero la mucha distancia de caminos y extensas navegaciones, y los repetidos peligros de tiempos y enemigos, a cuyas manos impensadamente pueden llegar las cartas, o prohijar alguno por suyo el trabaxo, que me ha costado muchos desvelos: me detuvo en la execución. Reservando la manifestación, prueba, y experiencias observadas para quando llegue personalmente a sus Reales plantas. ${ }^{45}$

De este modo, la carta acaba por convertirse en lo que Muñoz perseguía: un suculento anzuelo. Ahora el destinatario tenía dos opciones. La más sensata, quizá, sería asumir que aquel fraile dominico, cuya existencia le era desconocida hasta entonces, era un farsante que tan solo quería escapar de las Filipinas a costa del tesoro real. La más venturosa sería confiar en su palabra y, juzgando la utilidad de sus aportes científicos para el imperio, facilitarle el retorno a la Península. Felipe IV, poniendo de manifiesto el papel absolutamente primordial que tenían las cuestiones navales, se decidió por la segunda.

El 17 de julio de 1663, el rey escribía a Diego de Salcedo, gobernador de Filipinas, ordenándole que diera licencia a fray Ignacio Muñoz para ir a España y dar cuenta del gran servicio que le había prometido. ${ }^{46}$ Quizá con alguna reserva, indicaba a Salcedo que oyera «primero sus proposiciones y enterado de ellas y de la calidad y fundamento que tubieren me informareis de lo que se os ofreziere en lo que refiere en su carta». ${ }^{47}$ Ese mismo día, también se envió una real cédula semejante al virrey de la Nueva España, Juan Francisco de Leyva y de la Cerda, ordenando que le concediera a Muñoz «pasaje y avío» para llegar a la Península. ${ }^{48}$ Salcedo no debió encontrar inconveniente alguno en las propuestas de Muñoz, por lo que todo parecía

45 «Carta de fray Ignacio Muñoz sobre que hace algunos años fue a la India Oriental...», AGI, Filipinas, 86, n. 29.

46 Gil, 1989, 248.

47 «Copia de la Real Cédula de 17 de julio de 1663 a Diego de Salcedo, gobernador de Filipinas, ordenándole que dé licencia a Fray Ignacio Muñoz para venir a España al efecto de dar cuenta de un servicio de importancia a la seguridad de la navegación», AGI, Filipinas, 86, n. 29. Cursiva, subrayado en el original.

48 «Copia de Real Cédula de 17 de julio de 1663 al virrey de Nueva España, ordenándole que cuando llegue a esa ciudad Fray Ignacio Muñoz desde las Filipinas, le dé licencia y el pasaje necesario para venir a España», AGI, Filipinas, 86, n. 29. 
estar burocráticamente cerrado y convenido para que el fraile abandonase definitivamente las Filipinas, esgrimiendo su inestimable labor científica como aval. Las trabas inherentes a una administración imperial de la dimensión de la española aún retrasaron su partida dos años, hasta agosto de 1665. El 17 de septiembre de dicho año, mientras Muñoz surcaba las aguas del océano Pacífico, se anunciaba en Madrid la muerte de Felipe IV. El trono era ocupado por su viuda, Mariana de Austria, ante la minoría de edad de Carlos II. Cinco meses después del óbito de su principal valedor, a principios de febrero de 1666, fray Ignacio Muñoz desembarcaba en Acapulco.

\section{Interludio: la escala en México}

La presencia de Muñoz en Nueva España acabará por provocar un intenso flujo documental entre México y Madrid, a causa de las sospechas que levantaron sus ambiguas intenciones. Los recelos de Antonio de Toledo y Salazar, segundo marqués de Mancera, virrey de la Nueva España desde el 15 de octubre de 1664, y las airadas protestas del fraile por el trato que de este recibía, constituyeron un espinoso episodio articulado en torno a la honestidad personal y científica del propio Muñoz.

Desde Acapulco, fray Ignacio se había dirigido al convento de Santo Domingo de la ciudad de México, donde el 14 de marzo se le notificó la real cédula por la cual se le concedía pasaje y avío para continuar su viaje a través del Atlántico. Servil, Muñoz escuchó su contenido y afirmó que la obedecía, y que, «dándole lugar su salud para poderse embarcar», estaba «presto de ir». ${ }^{49} \mathrm{Al}$ día siguiente, el virrey confirmó su aprobación a la partida de Muñoz, ordenando que retomase su viaje «sin dilazión alguna», embarcándose en la flota de Veracruz que partiría a principios del mes de abril. El 16 de marzo, Muñoz habría de escuchar de nuevo la referida cédula - ya que el virrey consideraba que había sido algo ambiguo en su primera declaración - y ratificó sus palabras de días atrás, reafirmando el fraile su disposición de emprender el regreso a España. Sin embargo, el dominico tenía otros planes.

Ese mismo día prestó declaración nuevamente ante el escribano receptor, comunicando que, en realidad, no se encontraba lo suficientemente

49 «Copia de la Real Cédula de 17 de julio de 1663 al virrey de Nueva España, y otros papeles despachados en México tocantes a Fray Ignacio Muñoz», 19 de marzo de 1667, AGI, Filipinas, 86, n. 29. 
fuerte de salud debido al poco tiempo que había tenido para descansar del viaje desde Filipinas y de sus múltiples travesías en años anteriores. No obstante, su edad avanzada y su estado físico podían no ser suficientes para justificar su permanencia en México; por ello, una vez más, Muñoz se vio en la necesidad de utilizar su obra científica como salvaguarda. La estrategia fue convencer a los poderes novohispanos de que un trabajo tan importante no podía correr el riesgo de perderse en un naufragio, por lo que sería muy conveniente hacer una copia que permaneciese a salvo en la ciudad de México. Consecuentemente, solicitaba que se invalidara la real cédula de 1663 y se le permitiese no embarcarse en esta ocasión. ${ }^{50}$ Francisco Calderón, oidor de la Real Audiencia de México, juzgó razonables sus argumentos y dictó sentencia favorable al dominico. ${ }^{51}$ El propio Muñoz selló hábilmente sus intenciones de permanecer en México en una carta dirigida a la reina regente, el 5 de abril de 1666, en la que le aseguraba que su estancia en Nueva España no se debía tanto a su estado de salud y su cansancio, sino al celo con el que debía proteger esos documentos hidrográficos que tan buen servicio harían. ${ }^{52}$

Las noticias en torno a Muñoz reaparecen justo un año después de su solicitud para permanecer en México. El 16 de marzo de 1667, el virrey Mancera dirigía una consulta a fray Luis de Orduña, padre provincial de los dominicos de México, acerca del paradero del religioso, de quien se decía que no estaba en su convento, inquiriéndole si se le había concedido licencia alguna para abandonarlo. ${ }^{53} \mathrm{Al}$ día siguiente, Orduña informó al virrey de que Muñoz «salía y entrava quando tenía necessidad, sin darme a mí parte ni al Padre Prior deste convento; y el aver faltado del no a sido con special lizencia mía ni del Padre Prior deste Convento, ni savemos la derrota que ha cojido ni a dónde se encamina». ${ }^{54}$

50 Idem.

51 «Carta del virrey de Nueva España avisando de la llegada de Fray Ignacio Muñoz desde Filipinas», México, 23 de marzo de 1666, AGI, Filipinas, 86, n. 29.

52 «Carta de fray Ignacio Muñoz sobre las diligencias que hizo desde 1660 para viajar de Filipinas a España con el fin de ofrecer un servicio importantísimo tocante a las navegaciones; cuenta cómo llegó a México en marzo de 1666 y que el virrey le dio licencia para pasar a España. Pide que se le paguen los gastos del viaje para llegar hasta la Corte. Con duplicado», México, 5 de abril de 1666, AGI, Filipinas, 86, n. 29.

53 «Copia de unos billetes que se intercambiaron entre el virrey de Nueva España y el provincial de los dominicos de México, acerca de fray Ignacio Muñoz», 16-17 de marzo de 1667, AGI, Filipinas, 86, n. 29.

54 Idem. Juan Gil (1989, 249), quizá desconociendo este documento, se fio de la palabra de Muñoz y asumió que tenía tal licencia de sus superiores. 
Esta debió ser la gota que colmó el vaso para el virrey Mancera que, el 20 de marzo de 1667, escribió una incendiaria carta a la reina regente vertiendo todas sus sospechas y recelos sobre el fraile dominico. Tras afirmar que las razones que Muñoz dio para no viajar en 1666 no eran más que «excusas», Mancera relata que a mediados de febrero de 1667 tuvo una audiencia con él, en la que le aseguró que ya se encontraba en perfectas condiciones para proseguir su viaje y que pensaba embarcarse en la flota de ese mismo año. Sin embargo, al día siguiente, el religioso volvió a personarse ante el virrey, notificándole que «se hallava falto de medios para tan largo viage» y exigiéndole una ayuda de costa. Mancera se negó, arguyendo que la real cédula de 1663 solo le facultaba para concederle licencia y pasaje, y que además existían «infinitas cédulas» que prohibían a los virreyes librar ayudas de costa; tan solo si le presentaba un memorial que revisase el fiscal de la Junta General de Hacienda podría otorgarle cierta asistencia. Ante esto, el religioso le respondió que le llevaría dicho memorial y le espetó que «si saliese mal despachado no sería culpa suya [del propio Muñoz] dejar de embarcarse en esta flota y malograrse con la dilación el ymportante servicio que tenía ofrecido». Nótese lo taimado de esta aserción, pues Muñoz estaba inculpando al virrey de cualquier retraso o perjuicio que pudiese sufrir en la reanudación de su viaje. Cohibido, Mancera le aseguró que esperaría el memorial y que, si la Junta de Hacienda no atendía a sus peticiones, él mismo le entregaría de su «hacienda el viático suficiente para llegar sin descomodidad a España». Como es lógico, Muñoz se marchó satisfecho de la audiencia. ${ }^{55}$

El relato de Mancera proseguía narrando cómo, pocos días después, tuvo lugar un tercer encuentro, en el que, contra todo pronóstico, Muñoz expuso que «sus achaques no le permitían embarcarse sin conozido riesgo de la vida». Por esta misma razón le había sido imposible copiar los papeles que había prometido dejar en poder del virrey, por lo que no consideraba necesario «apresurar su partencia asta tener respuesta de ciertas cartas que en la flota pasada havía escrito al Rey». Sorprendido, Mancera intentó convencerle de que reanudara su viaje, a lo que el fraile respondía con «nuevas y mayores escussas». El culmen de la reunión llegó cuando Mancera le expuso que, a tenor de la real cédula de 1663, sería lógico que «prosiguiese

55 «Carta del marqués de Mancera, virrey de Nueva España, dando cuenta de haber continuado algunas diligencias suaves con fray Ignacio Muñoz para persuadirle de que pasase a España a ejecutar el servicio que tenía propuesto, y que éste se había ocultado poco antes del despacho de esta flota. Expone la opinión que tiene sobre este religioso», México, 20 de marzo de 1667, AGI, Filipinas, 86, n. 29. 
y feneciese el viage asta Madrid o se bolviese a las yslas filipinas», a lo que Muñoz «mostró quedar poco gustoso» ${ }^{.56}$ Con este movimiento, Mancera había tocado una fibra sensible para el dominico.

Habiendo expuesto estos acontecimientos, el virrey dio rienda suelta a una incesante andanada de acusaciones. En primer lugar, enfatizó la gravedad de sus escapadas del convento donde residía, informando de que había desaparecido durante ocho días sin dar noticia a ninguno de sus superiores. Y, en segundo término, insinuó su participación en el intento de eregio ilícito encabezado por fray Diego de Collado en la provincia del Santo Rosario de Filipinas. Parece que el tiempo y la quema de documentos orquestada por Diego Collado y el arzobispo Guerrero habían surtido efecto, pues Mancera carecía de pruebas de la participación activa de Muñoz en tales sucesos. Es muy probable que, de haberlas tenido, se hubiera ensañado mucho más con el asunto. Sí confirmó, no obstante, que fray Ignacio no se adscribió a la provincia del Rosario - a diferencia del resto de religiosos amotinados - por su incapacidad de vivir bajo obediencia, y lo acusó de haber abandonado las Filipinas en secreto - lo cual sabemos que es falso por el permiso que le concedió Hurtado de Corcuera- y de haberse pasado a la región de la corona de Portugal. Según el virrey, Muñoz habría entrado en territorio luso sin «licencia de sus superiores seculares, ni regulares», y regresado a Manila también sin ella, «después de tan larga havitación y comercio entre sus reveldes». ${ }^{57}$

Entonces, Mancera cargó las tintas sobre el recurso más valioso del dominico: la honestidad de su labor científica. Habiéndole reconocido Muñoz como un hombre «inclinado a la ciencia de las Matemáticas», le había comunicado al virrey ciertas observaciones astronómicas, hidrográficas y magnéticas que intentaban «dar nuevos Dogmas y reglas a las navegaciones». A partir de estas, Mancera formó su opinión acerca del genio científico de Muñoz, que juzgó poco impresionante. En sus propias palabras, no encontraba en su obra «novedad grave, ni leve, que, en lo teórico, o en lo práctico, realce lo ya savido o resuelva lo dudoso, o descubra alguna luz de lo ignorado». ${ }^{58}$ Tales eran las sospechas albergadas por Mancera, que incluso se había molestado en ponerse en contacto con los frailes del entorno de Muñoz,

56 Idem.

57 Idem.

58 Idem. Tampoco ayudaba a mejorar la imagen del dominico que considerase que las Filipinas caían en realidad en la demarcación lusa del mundo, como se lo participó al virrey en la reunión de diciembre de 1666. Como señala Gil (1989, 248), esta fue una de las afirmaciones que más escandalizó al virrey. 
quienes le confesaron que «nunca ha sido su intento pasar a España, sino salir de Filipinas, y quedarse en estos Reynos, goçando las esempciones». Con todos estos argumentos sobre la mesa, el virrey sentenció: «Arguyo que la suficiencia deste religioso en la facultad que professa de las matemáticas es muy moderada; su genio poco inclinado a vivir sugeto a la obediencia, y sus passos, y resoluciones, dignas de atención; y con este conozimiento la pondré muy special en saver a dónde se encamina, y sino fuere vía recta a España se lo estorbaré asta tener otra orden de Vuesa Majestad». ${ }^{59}$

En resumen, la carta que Mancera dirigía a Mariana de Austria era un compendio de acusaciones veladas de traición, de insubordinación - a la Corona y a su orden religiosa- y de estar engañando a su monarca con falsos aportes científicos. Era, sin duda, la peor carta de presentación posible ante la flamante reina regente. Quizá sabedor de la existencia de la misiva, o quizá intuyendo que estaba en el ánimo del virrey escribir tan difamatorias líneas, Muñoz no se demoró mucho en redactar su propia versión de los acontecimientos y remitirla a Madrid. De este modo, Muñoz denunció los «procedimientos violentos» que el virrey había tenido con él, que le habían

obligado a retirarme secretamente con licencia de mis prelados a parte donde no lleguen a execución dichas violencias, tan indecentes a un hombre honrado hijo de algo [...], crecido en años, sacerdote, religioso de Santo Domingo, Maestro en ella, y admitido de la grandeza de V. Majestad por sus cédulas a su Real Servicio; que a ser con un delincuente, vil, y facineroso, se tendrían por bastantes porque personalmente me amenaçó que me embiaría a Filipinas y que no lo executaba luego porque ya no estaría la nao de aquellas Islas en el puerto de Acapulco: castigo que en este Reino se tiene por sobrado aún con los homicidas y públicos salteadores, y otros criminosos execrables e infandos: y para pasar a España me denegó el avío que V. Majestad le manda por su Real cédula: y me consta que ha dado órdenes en el puerto de la Vera Cruz para que no me dexen embarcar para yr a la Real preferencia de V. Majestad. ${ }^{60}$

Por la carta del padre provincial, Muñoz parece mentir cuando afirma que había abandonado el convento con permiso de sus superiores. Tampoco oculta, una vez más, el profundo desasosiego que le inspiraba un potencial retorno a las Filipinas. Contradecía también la versión de Mancera, quien había manifestado su deseo de que el dominico abandonase Nueva España, pues llegaba a afirmar que trabajó más lentamente en la copia de sus papeles hidrográficos porque le había dado la palabra al virrey «de esperarle

59 Idem.

60 «Carta de fray Ignacio Muñoz, sobre que se ha detenido en Nueva España...», México, 12 de abril de 1667, AGI, Filipinas, 86, n. 29. 
hasta acabar su oficio, para acompañarle a España». Desde su punto de vista, Mancera lo hostigaba porque había sabido de boca de otro dominico que Muñoz condenaba el apoyo del virrey al maestro fray Alonso de la Barrera para erigirse como nuevo padre provincial, reprobando una campaña que incluía «particulares conveniencias», «intereses pecuniarios» y prácticas simoniacas; según Muñoz, su delito había sido «no aplaudir esta materia» y «no cortejar en ella a dicho maestro». ${ }^{61}$

Y aún va más lejos el dominico, sugiriendo que el desdeñoso comportamiento del virrey hacia su persona y su obra se debe a su condición de fraile, pues las «experiencias prolongadas» que tiene de esos países le habían llevado a pensar «que algunos ministros tienen por insípido, infructífero o criminoso al religioso», mirándose «con menos atención» las materias del servicio que estaba prestando a la corona, y a él «casi con vilipendio». Consecuentemente, la parte final de la carta es una súplica a la reina regente para que sus ministros no le opriman y le permitan continuar su labor. Muy interesantes resultan las últimas líneas, en las que se cuida de avivar el interés sobre sus trabajos con una escueta actualización: entregará «seis o siete tomos Hydrográficos (que requieren tiempo largo)». ${ }^{62}$

Es difícil discernir qué es verdad y qué es mentira en las versiones de Muñoz y de Mancera. De hecho, adjunto a la misiva de 12 de abril de 1667 se encuentra un memorial que Muñoz presentó al virrey en el que condenaba el trato que de él estaba recibiendo, y en este mismo memorial se contradice Muñoz con la carta anexa, exponiendo que a finales de febrero de ese año le «había dado a entender V. Excelencia [Mancera] que con efecto se embarcase en la pequeña flota que estaba para partir ese año, en virtud solamente de las cédulas antecedentes a dicha súplica, siendo que no son compulsivas». Y él se había negado poniendo como excusa la copia de los documentos hidrográficos, lo cual es una nueva contradicción, pues en dicha epístola se queja de haber tenido que ralentizar su trabajo por aguardar al virrey. ${ }^{63}$

La hipótesis que se antoja más plausible, teniendo que contrastar informaciones tan contradictorias, es la que sigue. La gran prioridad de Ignacio Muñoz era evitar las Filipinas. Esto podría explicar la tranquilidad

61 Idem. Sobre fray Alonso de la Barrera, véase Pérez Puente, 2000, 147, n. 125.

62 «Carta de fray Ignacio Muñoz, sobre que se ha detenido en Nueva España...», México, 12 de abril de 1667, AGI, Filipinas, 86, n. 29.

63 «Copia de un memorial de fray Ignacio Muñoz al marqués de Mancera, virrey de Nueva España», 1667, AGI, Filipinas, 86, n. 29. 
con la que afronta su escala en México, sin ningún tipo de apremio por continuar viajando hasta Madrid. Sus constantes alusiones a lo avanzado de su edad y la fragilidad de su salud podrían tomarse como veraces, pero también es cierto que funcionan como excusa a la perfección. Muñoz sabía que en algún momento tendría que ir a rendir cuentas a la capital, pero unos años de paz en México no le harían ningún daño. Posiblemente contaba con pasar desapercibido ante las autoridades, pero se encontró con un virrey sagaz y desconfiado. Por otro lado, habría una segunda razón a considerar que justificaría su insistencia para permanecer en México: que no estuviera copiando sus supuestos trabajos hidrográficos, sino produciendo los originales. Recordemos que todo lo que Muñoz ofrece a la corona son promesas futuras de las que solo obtendría rédito si eran escuchadas. Por tanto, ¿qué sentido habría tenido hacer el esfuerzo de escribir semejante obra antes de que se le diese licencia para abandonar las Filipinas?

Así pues, cuando Muñoz apareció en la ciudad de México, Mancera se habría encontrado con un fraile sospechoso de haber participado en un grave motín en Filipinas, amparado por la corona a razón de un servicio etéreo, que había vivido veinte años en tierras enemigas, que se escapaba de su convento sin comunicarlo a sus superiores y que, para más inri, se negaba a continuar su viaje tal y como lo ordenaban sendas reales cédulas y él mismo. El virrey, por lo tanto, tenía razones de sobra para desconfiar del dominico. Si a esto le sumamos el rechazo de Muñoz a la candidatura de fray Alonso Barrera, se antoja muy lógico que Mancera intentara torpedear sus aspiraciones. Ahora bien, tampoco los argumentos del virrey brillan por su moralidad y honradez. Sabedor de que el talento científico de Muñoz es lo único a lo que puede agarrarse para mantenerse alejado de Filipinas, intenta cuestionarlo descaradamente en su misiva de 20 de marzo de 1667, aderezando estas acusaciones con otras relativas a su lealtad y conducta. Concluyendo, ambos desconfiaban y ambos mentían. Se estaba librando una guerra abierta en la ciudad de México entre un virrey y un humilde fraile dominico, que contaba con un aval sumamente poderoso: su genio científico en beneficio del imperio.

Mientras, el proceder de Ignacio Muñoz también despertaba recelos al otro lado del Atlántico. Los documentos de su caso fueron revisados por el Consejo de Indias entre 1666 y 1667. El 20 de abril de 1667, el fiscal del Consejo «contradijo [el permiso de licencia y avío para Muñoz] y pidió se mandase a este religioso usare de su despacho y que no pretendiese venir a costa de su Majestad a hacer una proposición que, será lo más cierto, sea de 
ninguna utilidad a su real servicio». ${ }^{64}$ Pese a la evidente desconfianza, tras una nueva revisión de los documentos del caso, se decidió darle otra oportunidad por decreto del 12 de julio de 1667, en el que se exhortaba a Mancera a averiguar cuán ciertas y provechosas eran las promesas de Muñoz. Para cuando se firmó dicho decreto, la demoledora carta de Mancera navegaba en dirección a Madrid, dejando muy claro lo que el virrey opinaba del dominico. La respuesta a aquellas líneas se sancionó el 27 de septiembre, ordenando el inmediato retorno del fraile. ${ }^{65}$ Mancera había ganado. Muñoz volvía a España con una reputación oscura y una credibilidad tremendamente resquebrajada.

El regreso de Muñoz a Madrid fue ratificado en dos reales cédulas, de 4 y 18 de octubre de 1667 . En la primera, se resolvía darle pasaje y avío, tanto para el viaje a España como para el trayecto entre Sevilla y Madrid. En la segunda, mucho más breve y expeditiva, se aprobaba el proceder de Mancera, y se le ordenaba que proveyese «embiarle a estos reynos en la primera ocasión que se ofrezca, en la capitana o almirante, con orden de que el General le entregue en la ciudad de Sevilla, en el convento de su Religión, y que dé quenta al Consejo de averlo ejecutado» ${ }^{66}$ La llegada de ambas cédulas a México fue notificada por el virrey los días 13 y 14 de mayo de 1668 en la villa de Tacubaya, y los procedimientos burocráticos que de ellas emanaban se iniciaron en julio del mismo año. Concretamente, el día 7 de ese mismo mes se le leyeron a Ignacio Muñoz, que debió percatarse de que su situación se había tornado un tanto delicada. Por ello, tras escucharlas y ratificar que las obedecía, el día 16 de julio se apresuró a presentar sin tapujos toda la grandeza científica de su servicio, que se componía

de toda la Hidrografía universal de todo lo navegado en el océano por las costas, yslas y estrechos de todas las quatro partes del mundo, así por nuestra nación española como por las estrangeras de más experiencia; la mayor parte con las entradas de los ríos, varras y puertos, sus fondos, bancos, surgideros, señas, valissas, conocimientos perspectivos, tiempos, mareas, corrientes, variaciones de las agujas y sus derotas, y navegaciones

64 «Relación de lo que parece por los papeles inclusos sobre la venida de fray Ignacio Muñoz desde Filipinas a la Corte que se traen por haber presentado memorial en la secretaría de Perú»; «Relación sobre la pretensión de fray Ignacio Muñoz»; «Carta de fray Ignacio Muñoz sobre las diligencias que hizo desde 1660 para viajar de Filipinas a España...», México, 5 de abril de 1666, AGI, Filipinas, 86, n. 29.

65 En la copia del real decreto de 27 de septiembre el año está omitido, pero todo parece apuntar a que se trata del mismo 1667. «Relación de lo que parece por los papeles inclusos sobre la venida de fray Ignacio Muñoz desde Filipinas a la Corte...», AGI, Filipinas, 86, n. 29.

66 «Copia de unos autos tocantes a este religioso», México, 19 de abril de 1669, AGI, Filipinas, 86, n. 29. 
por escrito, y lo que resta a tan menuda exacción toca únicamente al mar Mediterráneo y costa de la Nueva Francia y Nueva Yngalaterra en la América, que procurará dicho padre maestro perficionar con la misma exacción en España donde la copia con la experiencia y su solicitud darán el último cumplimiento a esta maquinosa obra que se estenderá toda a seis o siete tomos de cartas náuticas de folio de marca. Aconpañaranse estos volúmenes de un tomo expecial de el arte de navegar, práctica, y especulativa e instrumental, exacta y perfeta, clara, y fácil para nuestros pilotos prácticos, copiossa de muchas tablas modernas y universales, reformando los graves defectos y conficciones que se hallan en los Artes que an escripto hasta este tiempo nuestros españoles, ocasionando peligrosos hierros. Ofreze también un nuevo astrolatico [sic], con que se observe el sol con toda facilidad y exación, hasta minutos, de cuya demostración y fábrica ha ofrecido a V. E. un opúsculo y pudiera hazer otro con la misma demostración, para fabricar otro instrumento no menos exacto para observar la variación de la aguja. ${ }^{67}$

Hasta ahora, Muñoz se había limitado a suministrar con cuentagotas escuetos detalles de los avances de sus proyectos, pero la situación en la que le había puesto el virrey Mancera lo obligaba a publicar sin reparos los entresijos de su labor científica. Tras esta declaración, el oidor responsable del caso, que continuaba siendo Francisco Calderón y Romero - quien ya se había mostrado proclive al dominico en 1666-, tenía la información necesaria para escribir un parecer muy favorable a Muñoz; y así lo hizo el 24 de julio de 1668, defendiendo el servicio del fraile en los siguientes términos:

Si lo consiguiese con la puntualidad que ofrece [el servicio], y a satisfación del Real Conssejo y con aprovación de personas inteligentes, será de grandísima importancia para las empresas, viajes, y seguridad de las armadas de su Majestad y comercio de los mercaderes del norte y del sur; y principalmente del mar del sur, en que por ser menos conocida y descubierta su navegación y no aver en él la frequencia de comercio que en el mar del norte y mediterráneo, apenas ay carta para las navegaciones ordinarias que se hazen deste Reyno desde el Puerto de Acapulco para Filipinas, y de aquellas Yslas para acá con los riesgos y atrasamientos que se an experimentado, gobernándose los pilotos por la experiencia y fantasía, sin punto ni fixesa en sus navegaciones; y así tengo por muy del servicio de su Majestad que reconociendo V. E. con su grande experiencia y inteligencia de las navegaciones de gran parte del mar del sur los papeles y relación que hace el padre maestro fray Ignacio Muñoz y ser tan útiles como propone, se sirva V. E. de alentarle a que desenbarazado de otras qualesquiera ocupasiones se aplique a esta $[\ldots]^{68}$

Y finalizaba constatando el regreso de Muñoz a España en la próxima flota, que partiría de Veracruz en mayo de 1669. Sin embargo, el fraile aún realizaría su penúltimo movimiento controvertido en el inmediato mes de

67 Idem.

68 Idem. 
agosto. Ese mismo año de 1668 falleció Diego Rodríguez, catedrático de Astrología y Matemáticas de la Universidad de México. Cuando la plaza salió a concurso tan solo se postuló un pretendiente: Ignacio Muñoz, con la venia del provincial de los dominicos. Según María Luisa Rodríguez-Sala, la plaza le fue otorgada porque «el rector y los conciliarios lo consideraron eminente en esta facultad, con la circunstancia de que se prorrogaron los edictos con término abierto, para que corriesen hasta que hubiese opositores». ${ }^{69}$ Este carácter previsiblemente transitorio del nombramiento encajaba a la perfección con la situación que vivía un Muñoz que ya había confirmado su inminente regreso a España. Con todo, mantuvo los honores de la cátedra hasta 1672, cuando fue sustituido por Luis Becerra Tanco. Pensar que Muñoz se prestó a ocupar la cátedra para atarse a México no parece del todo razonable; de igual modo, sería demasiado inocente considerar que lo hizo de forma absolutamente desinteresada. Resulta obvio que este nombramiento reforzaba su estatus y podría ser de utilidad en el futuro.

El último tira y afloja de Ignacio Muñoz con las autoridades virreinales tuvo lugar en marzo de 1669, dos meses antes de su partida. Esta vez se debió exclusivamente a avatares crematísticos, pues quería cerciorarse de que la corona le prestaría un socorro monetario de su agrado para llegar a Madrid. El 20 de marzo comunicaba que se hallaba sin recursos y, para conseguir la merced de la monarca regente, se amparó en su grado honorífico de maestro de Teología, la nobleza de su sangre, su avanzada edad, sus achaques por haber navegado tantos años en servicios hechos a su majestad y, por supuesto, su cargo de catedrático en propiedad de la Universidad de México. Tras ser revisadas por el fiscal las reales cédulas de octubre de 1667, el 1 de abril se acordó librar a Muñoz un socorro de seiscientos pesos. ${ }^{70}$ Por increíble que parezca, el dominico respondió algunos días después harto disconforme, argumentando que semejante cuantía no era suficiente para cubrir todos los gastos del viaje y solventar su situación de «suma pobreza». La expeditiva respuesta del fiscal — que a duras penas habría dado crédito a estas palabras - se firmó el 9 de abril, indicando que «el socorro de seiscientos pesos que se mandó dar al padre maestro fray Ignacio Muñoz es el competente para el pasaje a los reinos de España», y que «de no cumplir las reales ordenes de su majestad y lo que se le ha rogado y encargado tantas vezes por este govierno embarcándose en esta flota surta

69 Rodríguez-Sala, 2004, 91.

70 «Copia de unos autos tocantes a este religioso», México, 19 de abril de 1669, AGI, Filipinas, 86, n. 29. 
en el puerto de la Veracruz, se probeerá de remedio eficaz». Era el último aviso. Tan lapidarias líneas reflejan a la perfección el hastío que debía estar despertando el caso de Ignacio Muñoz. Si bien no se especifica cuál sería ese «remedio eficaz», se intuye que algo nada halagüeño, por lo que este agachó las orejas, afirmando el 19 de abril que daría «cumplimiento con rendida obediencia, sin reparar en ningunas incomodidades propias». ${ }^{71}$ Finalmente, el 21 de abril de 1669, Antonio de Toledo y Salazar, segundo marqués de Mancera y virrey de la Nueva España, informaba a la reina regente que el dominico se embarcaba en la capitana de la flota comandada por el general don Henrique Enríquez, y que se le habían entregado seiscientos pesos con fianza, tal y como había sido acordado previamente. ${ }^{72}$ La escala de Ignacio Muñoz en México había concluido.

\section{Sospechas, juicios y recompensas}

Fue el propio Muñoz quien, el 30 de enero de 1670, informaba a Mariana de Austria de que su viaje había transcurrido sin inconvenientes aparentes y que se encontraba en las costas españolas. Comunicaba que, a su llegada a Sevilla, se dirigiría al convento dominico de San Pablo y que permanecería allí hasta nueva orden de la reina regente. ${ }^{73} \mathrm{~A}$ la luz de estas líneas, no es menester añadir que cada paso del fraile estaba siendo cuidadosamente vigilado por las instituciones españolas. La orden para que Muñoz se desplazase a la corte se emitió el inmediato 14 de marzo ${ }^{74}$ pero los asuntos concernientes a su servicio no se trataron hasta julio de ese mismo año, por lo que es probable que este solo llegase a Madrid en mayo o junio. El día 11 de julio se expusieron en el Consejo de Indias los detalles de la obra científica del dominico, quien había confesado que aún se demoraría dos años en terminarla, y solicitaba que se le socorriese de la Real Hacienda con lo necesario para culminar su servicio. ${ }^{75}$ Es probable que fuera en este punto cuando las sospechas en torno a Muñoz alcanzasen su momento más

71 Idem.

72 «Carta del virrey de Nueva España, avisando que pasa a España fray Ignacio Muñoz», México, 21 de abril de 1669, AGI, Filipinas, 86, n. 29.

73 «Carta de fray Ignacio Muñoz, avisando de que ha llegado desde Nueva España en la Capitana de la flota, y que se quedará en el convento de San Pablo de Sevilla hasta ser llamado a la Corte para ejecutar el servicio que tiene propuesto», 30 de enero de 1670, AGI, Filipinas, 86, n. 29.

74 «elación de lo que parece por los papeles inclusos sobre la venida de fray Ignacio Muñoz desde Filipinas a la Corte...», AGI, Filipinas, 86, n. 29.

75 «Resumen del memorial», 11 de julio de 1670, AGI, Filipinas, 86, n. 29. 
crítico. Así lo prueba la resolución tomada en el Consejo el 21 de julio de 1670, por la cual se mandaba informar al provincial dominico de Castilla de «lo que escrive el Virrey del natural y andamientos de este religioso, y que haviendo venido a estos Reynos para el efecto que se le ordena, se tiene por conveniente que no salga de esta provincia», y se exhortaba al superior de su convento a que «esté con particular cuydado y recato» en lo que a sus ausencias se refiere. ${ }^{76}$

Se ordenó también a Lorenzo Matheu, oidor del Consejo de Indias, que escuchase la proposición de Muñoz y que «la comunicase con el cathedrático de Matemática de la Compañía de Jesús para reconocer la sustancia y fundamento de ella, y dar quenta al Consejo de lo que resultare de esta diligencia». ${ }^{77}$ Ahora, la suerte de Muñoz dependía de un solo hombre, y no de uno cualquiera. El catedrático de matemáticas de la Societas Iesu en aquellos años era José de Zaragoza y Vilanova, uno de los más brillantes matemáticos del siglo XVII $;^{78}$ si Muñoz había mentido sobre la utilidad o magnitud de su obra en ciernes, Zaragoza lo sabría al instante, con lo que el dominico se precipitaría hacia un escenario de lo más incierto.

La tensa situación en la que se encontraba Muñoz recibió un balón de oxígeno más que necesario el 5 de agosto de 1670, gracias a una carta de fray Pedro Álvarez Montenegro, provincial dominico de la provincia de Castilla y confesor del rey ${ }^{79}$ dirigida a Francisco Fernández de Madrigal, secretario del Consejo de Indias. En ella defendía a Muñoz como «uno de los más brillantes discípulos del convento de San Pablo de Valladolid», y se valía del testimonio de Juan Polanco, definidor de la provincia del Rosario, ${ }^{80}$ para ratificar el buen progreso que habían seguido sus labores cosmográficas. ${ }^{81}$ Montenegro, que sabía cómo funcionaban los entresijos de la corte madrileña, no dudó en instruir a Muñoz sobre cómo debía desenvolverse a la hora

76 «Memorial del maestro fray Ignacio Muñoz, de la Orden de Santo Domingo, catedrático de Matemáticas de la Universidad de México, sobre la necesidad de perfeccionar el Arte de la Náutica, que tanto importa para la seguridad de las posesiones españolas...», 21 de julio de 1670, AGI, Filipinas, 86, n. 29. Todas estas precauciones se las transmitió el secretario del Consejo al padre provincial, «Informe sobre Fray Ignacio Muñoz», Madrid, 22 de julio de 1670, AGI, Filipinas, 330, leg. 6, ff. 217r-220r.

77 «Memorial del maestro fray Ignacio Muñoz», 21 de julio de 1670, AGI, Filipinas, 86, n. 29

78 Nuria Valverde $(1999,199)$ lo clasifica como «el mejor matemático del XVII con Juan Caramuel Lobkowitz», además de destacar la magnitud de su obra, que «hizo de Zaragoza uno de los matemáticos más celebrados de la época, aunque particularmente fue reconocido por haber escrito una de las mejores astronomías del momento».

79 Gil, 1989, 250.

80 «Ensayo de Bibliografía de la Prov. Del Smo. Rosario en Filipinas, China, Japón, Formosa y Tungkin. P. M. Velasco, O. P. Tomo II», APDA, 5B-Izquierda, Documentación Diversa, tomo 140, 140. 81 Gil, 1989, 250. 
de presentar sus proyectos. Habiéndole recibido en la corte y «examinado su intento», le señaló «que mirase como se empeñaba, que advirtiese que estaba en un teatro mui público, que sentiría mucho que un religioso dominico hijo de mi convento fuese reputado en Madrid por uno de los noveleros de Corte». ${ }^{82}$ En otras palabras, en aquel teatro tan público de nada serviría su buen hacer científico si se dejaba pisotear por aquellos que despectivamente denomina «noveleros de Corte». Continuaba informando el padre provincial de que Muñoz debería haberse instalado en el convento de Santo Tomás de Madrid, pero, debido a la falta de espacio, fue enviado a la hospedería de la Pasión, en la propia corte. ${ }^{83}$ Allí, según Montenegro, seguía dedicándose íntegramente al estudio, trabajando sin descanso muchas noches hasta las dos o las tres de la mañana. El provincial volvía entonces sobre la orden del Consejo de «tener cuidado» con aquel religioso, exponiendo que, si dicha cautela se extendía a cerciorarse de que Muñoz no se fugaba, no podía dar más seguridad que las referidas noticias. Y añadía — con cierta acritudque, para extender su vigilancia sobre Muñoz, tendría que apresarlo sin causa, estimando que el fraile debía gozar de libertad para «dar cuenta de su persona». La carta llega a su fin con unas líneas protectoras hacia Muñoz, sugiriendo Montenegro que, si sus estudios y promesas nada aportaran a lo ya sabido en materia hidrográfica, él mismo lo enviaría a uno de sus conventos, donde lo aguardarían con los brazos abiertos. ${ }^{84}$

Unos días más tarde, el padre Zaragoza habría de remitir a Lorenzo Matheu la carta con las conclusiones extraídas de su reunión con Muñoz, quien únicamente necesitaba que alguna de sus proposiciones científicas fuera aprobada como novedosa y provechosa para la corona española. El jesuita iniciaba su misiva reflejando la gravedad del asunto: «Para maior satisfación mía y seguridad de mi conciencia he tomado el tiempo necessario para meditar la relación que devía hazer a V. Sa. de las cosas que ofrece el Padre Maestro Fr. Ignacio Muñoz en su memorial». ${ }^{85}$ Para después, en

82 «Carta de fray Pedro Álvarez de Montenegro a Francisco Fernández de Madrigal, respondiendo al papel sobre el cuidado y recato con que convenía estar con fray Ignacio Muñoz», 5 de agosto de 1670, AGI, Filipinas, 86, n. 29.

83 Idem. «Memorial del maestro fray Ignacio Muñoz...», 21 de julio de 1670, AGI, Filipinas, 86, n. 29.

84 «Carta de fray Pedro Álvarez de Montenegro a Francisco Fernández de Madrigal...», 5 de agosto de 1670, AGI, Filipinas, 86, n. 29.

85 «Carta del padre José Zaragoza, de la Compañía de Jesús, a Lorenzo Mateo y Sanz, dando cuenta de lo que se le ofrece sobre las proposiciones que ha hecho fray Ignacio Muñoz acerca de la navegación de las Armadas de las Indias, ofreciendo cartas náuticas ajustadas con toda perfección y claridad», Madrid, 8 de agosto de 1670, AGI, Filipinas, 86, n. 29. 
cuatro puntos, sentenciar acerca de la utilidad de lo que Muñoz ofrece: la posibilidad del dicho servicio, la suficiencia del sujeto, y el modo y orden de la ejecución. Respecto a lo primero, declara que

la utilidad del arte de navegar exacta, perfecta, clara y fácil, y de las cartas náuticas ajustadísimas no necesita de ponderación, pues ha sido tan deseada de nuestros Reyes Católicos como lo testifican todos los boreales en sus escritos; y si esta se pudiese conseguir con la exacción, perfección, claridad y facilidad que se ofrece, no ay Monarca en la Europa que perdonase a gasto alguno, porque obra tan insigne y deseada saliese a luz debaxo su protección. ${ }^{86}$

Evidencia Zaragoza, por tanto, el papel absolutamente esencial del conocimiento náutico para los imperios europeos de su tiempo. Y justifica, además, cualquier gasto que la corona española hubiera hecho en apostar por los servicios de Muñoz. Sin embargo, en cuanto a las posibilidades que este tenía de cumplir sus promesas, el matemático no ocultaba sus dudas:

La possibilidad prática de lo que se ofrece es a mi juizio superior al ingenio, diligencia y observaciones no solo de un honbre, sino de muchos, aunque sus vidas se dilaten un siglo: Esta verdad se reconoce en Europa, cuias longitudes y latitudes aún no están ajustadas, siendo verdad que este siglo hasta oy ha tenido los maiores observadores, instrumentos más exactos y maior copia de observaciones, principalmente de eclipses, que tuvieron juntos los diez precedentes siglos. De donde se infiere que 30 años de experiencia y esta interrumpida con varios y diferentes enpleos no puede bastar para la corrección perfeta de la navegación y cartas náuticas ajustadíssimas de todo lo navegado en el orbe: y como después dize el memorial, de todo lo navegado en el océano y mediterráneo por las costas, islas y estrechos de todas las quatro partes del mundo. ${ }^{87}$

Los argumentos del padre Zaragoza para cuestionar al dominico eran sólidos. Ni siquiera las latitudes y longitudes europeas habían sido ajustadas con precisión, pese a haberse empeñado en ello las mentes más brillantes del siglo XVII... ¿Cómo era posible que un solo hombre, que además había llevado una vida tan dispersa, hubiese resuelto los problemas de la navegación y las cartas náuticas de la totalidad del orbe en escasas tres décadas? Zaragoza — al igual que el propio Muñoz — sabía que era inverosímil. Afrontando la realidad, el fraile confesó que las cartas náuticas que estaba compilando no eran originalmente suyas, sino que las había copiado minuciosamente de originales holandesas. ${ }^{88}$ No obstante, a juicio de Zaragoza,

86 Idem. Cursiva, subrayado en el original.

87 Idem. Cursiva, subrayado en el original.

88 Según Ocio y Neira (2000, 64), habría sido durante su estancia en Goa cuando Muñoz tuvo relaciones con los holandeses, examinando allí las cartas geográficas de los nuevos descubrimientos. 
se debía valorar el cuidado que Muñoz había puesto para «observar quando llegava a los puertos la verdad de las cartas, y en lo que pudo observar dize [que] las halló puntuales; de donde, con bastante probabilidad, se puede inferir que en las otras cosas que contienen serán verídicas, aunque no estén aprobadas por la experiencia». ${ }^{89}$ Refería, asimismo, una carta que debía haber producido Muñoz, de la cual no existía más prueba que la palabra del fraile pucelano. Circunstancia que aprovecha el matemático para expresar su confianza en la integridad del examinado, declarando que es «persona religiosa y grave», y que no halla «razón porque no se le deva entero crédito». La parte final del informe está dedicada a valorar la utilidad de los aportes de Muñoz en materia de variación de la aguja y su «Arte de Navegar, práctica y especulativa». Sobre lo primero, dictaminó Zaragoza que

las observaciones de la variación de la aguja es cierto que no conduzen para la corrección de las cartas, ni son suficientes para la navegación perfeta; pero no ay duda que conduzen para adelantar esta facultad tan útil a la república, y por esso todos los authores modernos encargan a los Pilotos que dejen escritas sus observaciones, pues aunque unas no concuerden con otras, la multitud dellas puede servir para tomar un medio más próximo a la verdad y menos peligroso en la execución: con que por esta parte son estimables las del Padre Maestro. ${ }^{90}$

Y respecto a lo segundo, fue el propio Muñoz quien confesó que «no tenía otros preceptos que los escritos ya por los authores modernos latinos, solo que los escritores españoles van en esta parte mui diminutos». Aun así, Zaragoza consideró que su aportación «será útil para los pilotos españoles; y las tablas de los rumbos, aunque no tengan novedad más que el ser copiosas, serán de mucha conveniencia para la navegación». Dejó para el final el jesuita lo que más le había impresionado del memorial: el novedoso astrolabio artesano, construido con grados muy grandes y que permitía una exactitud incluso de minutos en cualquier momento del día. Pero todas sus expectativas se desvanecieron cuando, al examinarlo, no halló «en el instrumento más precisión que en el astrolabio común», no encontrando razón alguna para aprobar el artefacto. ${ }^{11}$ En síntesis, al finalizar su juicio, de la ciclópea obra que Muñoz había ofrecido en 1660 quedaba un número indeterminado de cartas náuticas copiadas a los holandeses, ${ }^{92}$ algunas

89 «Carta del padre José Zaragoza...», Madrid, 8 de agosto de 1670, AGI, Filipinas, 86, n. 29.

90 Idem.

91 Idem.

92 Fue esta la aportación que Zaragoza encontró más significativa, sugiriendo que se comenzase el aprovechamiento de la obra con la impresión de esa parte en folio pequeño. Gil, 1989, 250. 
observaciones de la variación de la aguja y un «Arte de Navegar» de escasa originalidad que, no obstante, resultaría de utilidad para los pilotos españoles. Con todo, concluía Zaragoza que Muñoz tenía «las noticias suficientes, y dibuxo competente para el empleo», y que lo había reconocido «instruido de las noticias necesarias de esphera, astronomía, trigonometría y arithmética que piden las observaciones náuticas y de los preceptos que regularmente traen los autores para semejantes observaciones»..$^{93}$

Estas aseveraciones bastaban para sellar las intenciones de Muñoz de permanecer en la corte durante al menos dos años más, trabajando en su gran proyecto náutico. El 12 de agosto de 1670 se ponían en marcha los procedimientos para concederle una asignación de 300 ducados anuales para alimentos ${ }^{94}$ que disfrutaría alojado en alguno de los conventos dominicos de Madrid. Así, sus conocimientos científicos y su afilado ingenio no solo le habían abierto a Muñoz la puerta de salida de las Filipinas, sino también la de entrada a la corte madrileña, donde recibió el 20 de octubre de ese mismo año el título de Reformator Hydrographiae Universalis et Particularis. ${ }^{95}$

El rastro documental del tiempo que pasó Muñoz en la capital es más inconstante y difuso, aunque se evidencia su relevancia en ciertos asuntos de Estado. Por ejemplo, cuando el franciscano descalzo Miguel Juan Serret escribió a la monarca solicitando limosna para el hospital de Naturales de Manila — que había sido demolido cuando Muñoz aún se encontraba en Filipinas y reedificado en madera-, se le pidió al dominico que redactara un informe. ${ }^{96}$ Muñoz aprovechó la tesitura para hacer valer sus conocimientos sobre Manila, incluyendo en el expediente su planta, medida y un pequeño plano de la ciudad que había delineado en 1662 por orden de Sabiniano Manrique de Lara — gobernador de las Filipinas por aquel entonces - para fortificar la localidad frente a la amenaza del corsario Kuesing. ${ }^{97}$

93 «Carta del padre José Zaragoza...», Madrid, 8 de agosto de 1670, AGI, Filipinas, 86, n. 29.

94 «Nota de la secretaría sobre asignarse 300 ducados para alimentos de este religioso», 12 de agosto de 1670, AGI, Filipinas, 86, n. 29; «Consulta sobre sueldo para Ignacio Muñoz», 12 de agosto de 1670, AGI, Filipinas, 3, n. 17.

95 González, 1967, 411. Sobre el proyecto de Muñoz para perfeccionar la navegación de las flotas de Indias, véase Gil, 1989, 250-251.

96 «Carta de Miguel Juan Serret pidiendo limosna para el Hospital de Naturales de Manila», Manila, 20 de julio de 1670, AGI, Filipinas, 86, n. 30.

97 Idem. González, 1967, V: 409. Dicho plano se conserva exento del informe, con referencia «Descripción geométrica de la ciudad y circunvalación de Manila y de sus arrabales al Consejo de las Indias», 8 de noviembre de 1671, AGI, Mapas y planos, Filipinas, 10. Disponible en: http://pares.mcu. es/ParesBusquedas20/catalogo/show/18779?nm [Consultado: 30/10/2020]. 
Con posterioridad, el 15 de abril de 1674, el fraile entregó al Consejo de Indias el citado parecer «sobre la manutención y extensión de fe en la cordillera de las Islas Marianas, y sus confinantes, y sobre el descubrimiento y conquista de las islas australes de Salomón». ${ }^{98}$

\section{El duque de Béjar, un mecenas complementario}

Pero no era oro todo lo que relucía en la corte madrileña, y precisamente oro era lo que le faltaba a Muñoz; ya el 13 de mayo y el 16 de noviembre de 1671 exigía que se le pagase el sueldo de medio año que aún no había recibido. ${ }^{99}$ Esta situación debió agravarse con el tiempo, pues Muñoz, contra todo pronóstico, acabó por buscarse un mecenas complementario a la corona. El elegido fue Manuel López de Zúñiga y Sarmiento de Silva, $\mathrm{X}$ duque de Béjar y Plasencia, Grande de España y caballero de la Orden del Toisón de Oro, a quien dedicó su Manifiesto geometrico, plus ultra de la geometria practica: addicion al IV libro de los Elementos de Euclides: construccion y demostracion geometrica del triangulo isosceles propio del heptagono regular y descripcion de la misma figura (Bruselas, 1684). El título de la obra ya evidencia el cambio de estrategia adoptado por Muñoz, obligado a adecuar la temática de la oferta científica al destinatario. La resolución de un problema matemático aparentemente irresoluble daría juego a un noble para alardear del genio matemático de su protegido, mientras que para Felipe IV y su imperio tendría escasa utilidad.

En el proemio de la obra, Muñoz presenta sus credenciales con todo lujo de detalles: «Maestro en Theologia [...] del Orden de Predicadores, Catedrático propietario de Matemáticas de la Real Universidad del Imperio Mexicano, ${ }^{100}$ y reformador por su Majestad de la Hydrografia Universal, y particular de todo quanto se navega en el Mar Océano, y en el

98 «Informe de fray Ignacio Muñoz, de la Orden de Santo Domingo, al Consejo de Indias sobre la evangelización de las Islas Marianas y sus confinantes, y sobre el descubrimiento y conquista de las Islas Australes de Salomón. 15 de abril de 1674», Madrid, AGI, Filipinas, 82, n. 22. Un borrador de este texto se localiza también entre las páginas de su obra «Derroteros de los mares de Marruecos, Canarias, América y Filipinas, y otros documentos» (BNE, ms. 7119), ambos analizados por Juan Gil (1989, 252-254). La copia conservada en el AGN, y transcrita por Reichert (2014), comparte título y contenido con los estudiados por Gil y está datada en 2 de octubre de 1675.

99 Gil, 1989, 251.

100 Huelga recordar que hacía más de una década que Muñoz había cedido la cátedra de Matemáticas de la Universidad de México. 
Mediterráneo». ${ }^{101}$ Como parte de su estratagema laudatoria relata cómo, seis años atrás, había participado al duque el procedimiento para resolver el problema geométrico que aborda en la obra, y que este lo había ejecutado con «singular brevedad y destreza». Tras ensalzar algo más las capacidades intelectuales de su patrón, Muñoz utiliza un recurso muy interesante para revalorizar su trabajo: la incapacidad de un gran matemático contemporáneo para solventar dichos cálculos. El nominado es Luís Serrão Pimentel (1613-1679), destacadísimo hombre de ciencia portugués que ocupó los cargos de cosmógrafo-mor y engenheiro-mor del reino luso. Según Muñoz, Serrão Pimentel habría confirmado por carta de 5 de mayo de 1677 la imposibilidad de resolver este interrogante geométrico, augurándole «grande gloria» al dominico si era verdad que había averiguado la escurridiza solución. ${ }^{102}$

Muñoz se cuidaba de defender la originalidad y «paternidad» sobre su hallazgo, urgiendo al duque que lo publicase cuanto antes para evitar que terceros se apropiasen de sus ideas. Oportunidad en la que el astuto predicador revela el anzuelo con el que había embaucado al duque: la elaboración de un «tomo grande» que titularía Nuevo Tesoro, y Plus ultra de la Geometria Practica, donde se executan, resuelven y demuestran muchísimos Problemas nuevos tocantes a las descripciones Geometricas de muchas Figuras regulares rectilíneas de ángulos, y lados de numero impar; oferta que habría de aderezar asegurando que nunca había considerado otro mecenas o protector que no fuera la «Real Grandeza, eximio valor, raro ingenio, singular memoria y talento supremo de V. Excelencia». ${ }^{103} \mathrm{El}$ dominico se lamentaba de no haber podido llevar esta obra a la imprenta por falta de medios y por «la poca curiosidad española en estas materias, con que nuestros libreros no entran en los gastos de estas impresiones, porque no reconocen el útil, y consumo de estos libros generalmente en España». ${ }^{104}$

Una vez que tenía al duque colmado de proposiciones y halagos, Muñoz se sinceró sobre las razones que le habían empujado a buscar su protección: se le adeudaban siete años del salario concedido por el Consejo de Indias en 1670. A pesar de ello, el fraile reafirmaba su fidelidad a la corona, asegurando que si cobrase no lo invertiría en la publicación del Manifiesto Geométrico, sino en la contratación de amanuenses que le ayudasen a poner

101 Muñoz, 1684, 1r. El proemio está fechado el 24 de junio de 1683

102 Ibidem, ff. $1 \mathrm{r}-4 \mathrm{r}$.

103 Ibidem, f. 4r-4v.

104 Ibidem, f. $5 \mathrm{v}$. 
en limpio su gran obra hidrográfica. En consonancia con sus habituales excusas, justificaba prolijamente el retraso en la impresión de la prometida obra Plus ultra de la Geometria Práctica. Parece ser que, unos meses antes de la redacción del proemio, el duque había escrito a la reina María Luisa de Orleans para que Muñoz remitiese la obra a Flandes, donde este se encontraba combatiendo. El dominico se escudó en «ocupaciones forçosas de muchos escritos» en servicio del rey, del Consejo de Indias y de la Junta Real de Obras y Bosques, habiendo tenido que trabajar como amanuense de sus propias obras. Así, como ya hiciera para retrasar la entrega de sus materiales hidrográficos cuando se encontraba en Filipinas y México, Muñoz justificó la demora por la copia del libro, necesaria para prevenir «la contingencia de su pérdida en el viaje». Una vez más, sobrevuela sobre estas líneas la sospecha de que Muñoz no hubiese terminado la obra original, como bien confiesa a regañadientes poco después, a la par que devuelve la esperanza a sus mecenas de que el texto sería publicado en el menor tiempo posible: «ya parece que tendré más lugar de sacar poco a poco dicha copia, y de remitirla en pliegos con sus figuras, para que se vayan abriendo las láminas, en quanto llega completamente todo el original, porque entonces se podrá imprimir brevísimamente todo el tomo». ${ }^{105}$

La publicación de la obra en 1684 confirmaría la satisfacción del duque con los trabajos de Muñoz y su interés en patrocinar al dominico. No obstante, este despertó menos admiración entre ciertos colegas matemáti$\cos ^{106}$ En el poco tiempo que Muñoz gozó de esta relación de patronazgo, el duque de Béjar demostró buenas dotes de mecenas, pues incluso sus oficiales en Flandes sabían de la vida y obra del predicador. Así lo confirma una carta de 24 de diciembre de 1685, firmada por el oficial Marcos Caballero Gallego en Namur (Bélgica), en la que felicitaba la Navidad al dominico, y le deseaba «prosperidad por muy dilatados años, acompañada de un arzobispado que le merecen las inimitables virtudes y prendas de

105 Ibidem, ff. 6r-6v.

106 Véase la severa reprimenda que recibió el Manifiesto en un impreso anónimo, atribuido a Jorge del Pozo, donde se refuta la validez de los postulados del dominico y se le acusa de soberbio por no haber considerado los trabajos de otros autores importantes, entre ellos el padre Zaragoza, que trataban la cuestión. Con especial crudeza, se ensañaba diciendo que las «proposiciones de triangulitos», en «la corte del gran rey de España, erario de las buenas letras y sciencias», son más bien «controversias de discípulos, que assumpto para darse a conocer un cathedratico; mas quando lo adorna V. P. con el Plus Ultra; no ay más que dezir, y es buen medio para que le conozcan». Responde Iorge del Poço desde la otra vida, como catedratico que fue de mathematicas en la Chanverga, al papel impresso en Bruxelas este presente año de 1684 sacado a la luz por el padre maestro fray Ignacio Muñoz..., c. 1684, BNE, VE/14/13. 
Vuestra Reverendísima [persona]» ${ }^{107}$ Muñoz nunca llegó a disfrutar de tal preeminencia, entre otras cosas, porque su intensa vida concluyó a finales de $1686 .{ }^{108}$ Pero si hubiera estado en la carrera por él habría sido un candidato a tener en cuenta, amparado por los múltiples recursos que su estancia en la capital le habría proporcionado. Al fin y al cabo, tras tres lustros en Madrid, fray Ignacio Muñoz debía ser todo un cortesano.

\section{Epílogo}

La publicación de Galileo Courtier. The Practice of Science in the Culture of Absolutism ${ }^{109}$ marcó un punto de inflexión a la hora de entender las relaciones entre ciencia y mecenazgo en el siglo XVII. Sumó adeptos y detractores casi a partes iguales, suscitando críticas de colegas de profesión por ciertos excesos y libertades en la interpretación de las fuentes. ${ }^{110}$ A pesar de todo ello, Galileo cortesano daba un paso de gigante en una dirección necesaria para la historia de la ciencia: entender que la actividad científica no podía producirse en un limbo de genialidad, sino que se desarrollaba al amparo de las más diversas circunstancias e instituciones. Así fue para el Galileo que dibujó Mario Biagioli, y así fue también para fray Ignacio Muñoz. Como es obvio, los contextos en los que produjeron su obra científica son claramente muy diferentes, al igual que lo eran los mecenas a los que querían impresionar. Galileo desarrolló su vida y obra en Italia, privilegiado por varios bienhechores - entre los que se destacaron los Medici-, mientras que Muñoz peregrinó por todo el mundo hasta afincarse en Madrid al servicio de la corona española. Diferentes patrones, misma estrategia: fascinarlos con algo único y sumamente beneficioso para sus intereses. Así, mientras Galileo bautizaba los cuatro satélites que orbitan

107 «Carta del oficial Marcos Caballero Gallego a fray Ignacio Muñoz, felicitándole las pascuas, comentando el destierro de [Manuel Diego López de Zúñiga, X] duque [de Béjar] y las penurias de las tropas destacadas en Flandes», Namur, 24 de diciembre de 1685, Archivo Histórico de la Nobleza, Toledo, Osuna, CT. 34, D. 4.

108 Según Fabián Navarro en su Historia del Convento de San Pablo de Valladolid, Muñoz habría fallecido en 1685 (cit. en González, 1967, V: 410). No obstante, la última anotación manuscrita con caligrafía de Muñoz en los «Derroteros de los mares de Marruecos...» (BNE, ms. 7119, f. 272v) corresponde a octubre de 1686: «el virrey tiene de sueldo 39 mil pesos; assi (?) D. Joseph de Avellaneda en octubre, año de 1686». Consideramos por tanto los últimos meses de 1686 como el arco temporal más probable para la muerte del dominico.

109 Biagioli, 2008 [1993].

110 Entre las más feroces, se encontraba la firmada por Michael H. Shank, 1996. 
en torno a Júpiter en honor de Cosme II de Medici, Ignacio Muñoz prometía a Felipe IV una serie de recursos técnico-científicos para robustecer la presencia española en aguas del sudeste asiático. Dos maniobras totalmente disímiles, pero perfectamente adaptadas para complacer a sus destinatarios.

Como muy acertadamente señala Ignacio Díaz Hernández, ${ }^{111}$ durante el siglo XVI existió en la Península una «relación casi inextricable entre ciencia e intereses del monarca», realidad que apenas mudó en el siglo XVII. Los objetivos del científico debían ser los del monarca y, por ende, los del imperio. Consecuentemente, era la ciencia náutica la llave para reclamar el favor de la corona. Pero Muñoz ni se encontraba en España, ni se había labrado un nombre a partir de sus conocimientos náuticos, ni estaba avalado por ningún piloto mayor ni cosmógrafo de la Monarquía; en definitiva, no podía ser más invisible a ojos de Felipe IV. Aun así, consiguió escapar de las Filipinas, pasar unos años en México y asentarse en Madrid hasta el fin de sus días, todo ello con la venia de Felipe IV y Mariana de Austria, absortos por la promesa de una utópica obra que nunca llegaría a concluir. Y no contento con esto, el dominico probó su versatilidad en la adquisición de mecenas, cautivando también con sus promesas al duque de Béjar. Es aquí donde podríamos encontrar presentes más similares a los ofrecidos por Galileo, pues los destinatarios pertenecen a grupos de posición social equiparable. Consciente del cambio de público, Muñoz adaptó sus conocimientos matemáticos para producir obras más acordes al ámbito nobiliario. Sin embargo, los retrasos en las entregas, excusas y ardides del dominico continuaron siendo la tónica en la relación con su mecenas complementario.

La vida de Ignacio Muñoz pone de manifiesto, por un lado, el papel primordial que la ciencia náutica ocupaba en el imperio español y, por otro, la cantidad de puertas que el conocimiento científico podía abrir en dicho imperio si era utilizado de manera apropiada. Finalmente, la escasa atención recibida por Ignacio Muñoz — a pesar de su obra y sorprendente trayectoria vital - es también una llamada de atención a la necesidad de profundizar en la actividad científica producida en servicio de la Monarquía hispánica durante el siglo XVII.

111 Díaz Hernández, 2010, 13. 


\section{Referencias bibliográficas}

Aduarte, Diego de y González, Domingo, Historia de la Provincia del Santo Rosario de Filipinas, Japón y China de la Sagrada Orden de Predicadores, 2 tomos, Zaragoza, Imprenta de Domingo Gascon, 1693.

Biagioli, Mario, Galileo cortesano. La práctica de la ciencia en la cultura del

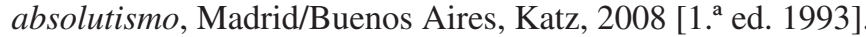

Bouza, Fernando Jesús, «Primero de diciembre de 1640: ¿una revolución desprevenida?», Manuscrits, 9, Barcelona, 1991, 205-225.

Cervera Jiménez, José Antonio, «Los misioneros españoles como vía para los intercambios científicos y culturales entre el Extremo Oriente y Europa en los siglos XVI y XVII», Memoria presentada para optar al título de Doctor en Ciencias dirigida por Mariano Hormigón Blánquez, Zaragoza, Universidad de Zaragoza, 1999.

Colín, Francisco y Pastells, Pablo (eds.), Labor evangélica de los Obreros de la Compañía de Jesús en las Islas Filipinas, 3 vols., Barcelona, Imprenta y Litografía de Henrich y Compañía, 1904.

Díaz Hernández, Ignacio, «Estudio preliminar y transcripción del manuscrito de Diego Ramírez de Arellano "Reconocimiento de los estrechos de Magallanes y San Vicente, con algunas cosas curiosas de navegación (1621)», Tesis doctoral dirigida por Víctor Navarro Brotons, Valencia, Universidad de Valencia, 2010. Disponible en: https://roderic.uv.es/handle/10550/23453 [Consultado: 30/10/2020].

González, José María, Historia de las Misiones Dominicanas de China, 5 vols., Madrid, Imprenta de Juan Bravo, 1967.

Gil, Juan, Mitos y utopías del Descubrimiento. 2. El Pacífico, Madrid, Alianza Editorial, 1989.

Martín Rubio, M. ${ }^{a}$ Carmen, «Dos derroteros para la navegación a Canarias de los siglos XVI y XVII», en Morales Padrón, Francisco (coord.), XII Coloquio de Historia Canario-Americana, vol. 2, Las Palmas de Gran Canaria, Cabildo Insular de Gran Canaria, 1998, 43-56.

Muñoz, Ignacio, Manifiesto geometrico, plus ultra de la geometria practica: addicion al IV libro de los Elementos de Euclides: construccion y demostracion geometrica del triangulo isosceles propio del heptagono regular y descripcion de la misma figura, Bruselas, Francisco Foppens, 1684.

Navarro Brotons, Víctor, «La Libra astronomica y philosophica de Sigüenza y Góngora: la polémica sobre el cometa de 1680», Cronos, 2:1, Valencia, 1999, 105-144.

Ocio, Hilario y Neira, Eladio, Misioneros Dominicos en el Extremo Oriente, 1587 1835, Manila, Life Today Publications, 2000.

Pérez Puente, Leticia, Universidad de doctores. México. Siglo XVII, México D. F., Universidad Nacional Autónoma de México, 2000. 
Reichert, Rafal, «La transcripción del manuscrito de fray Ignacio Muñoz sobre el proyecto de manutención y extensión de la fe católica en las Islas Marianas, y del descubrimiento y la conquista de las Islas Salomón, siglo XVII», Estudios de Historia Novohispana, 51, Ciudad de México, 2014, 133-163.

Rodríguez-Sala, María Luisa, «Fray Diego Rodríguez: Astrónomo-Astrólogo-Matemático, precursor de la modernidad científica nacional», en Rodríguez Sala, María Luisa (coord.), Del estamento ocupacional a la comunidad científica: astrónomos-astrólogos e ingenieros (siglos XVII al XIX), Ciudad de México, Universidad Nacional Autónoma de México, 2004, 85-130.

Shank, Michael H., «How Shall We Practice History? The Case of Mario Biagioli's "Galileo, Courtier"», Early Science and Medicine, 1:1, Leiden, 1996, 106-150.

Tronu Montané, Carla, «Los primeros materiales para el estudio del japonés realizados por un español: Diego Collado OP y la misión japonesa en el s. XVII», en Agud Aparicio, Ana et al. (eds.), Séptimo Centenario de los Estudios Orientales en Salamanca, Salamanca, Ediciones Universidad de Salamanca, 2012, 755-763.

Valverde, Nuria, «El prodigio y su medida», en Lafuente, Antonio y Moscoso, Javier (eds.), Madrid, ciencia y corte, Madrid, Consejería de Educación y Cultura/Universidad de Alcalá, 1999, 195-202. 